\title{
Comparative analysis of hemosorbents obtained at different modes
}

\author{
Assiya Nuraly ${ }^{1,2}$, Sestager Akhnazarov ${ }^{1,2}$, Esin Apaydin-Varol ${ }^{3}$, \\ Ulpan Amzeyeva ${ }^{1}$, Alibek Mutushev ${ }^{1}$
}

\footnotetext{
${ }^{1}$ Scientific - Production Technical Center "Zhalyn" 11 Pavlodarskaya St.), Almaty, Kazakhstan.

${ }^{2}$ Al-Farabi Kazakh National University (71 al-Farabi St.), Almaty, Kazakhstan.

${ }^{3}$ Anadolu University (Yeşiltepe, Yunus Emre Kampüsü, 26470 Tepebaş1/Eskişehir), Eskisehir, Turkey. e-mail: assiya.nuraly@bk.ru
}

\section{ABSTRACT}

When using hemosorbent laminar flow, a large active area of sorbents is used, the trauma of the blood corpuscles decreases dramatically, the ash content of the saline solution is absent. One of the methods of solving environmental problems is to develop various materials based on industrial waste. In the article, the method of obtaining carbonized rice husks is described, the adsorption capacity for methylene blue was measured for the obtained sample, the morphological structure was examined, comparative analysis with analogs was carried out. The authors carried out research work, such as collecting information, selecting methods, conducting analysis, processing the results. Granular hemosorbents that have been used until recently penetrate the blood-forming elements, creating a mechanism for thrombosis that violates the integrity of the erythrocyte membrane.

The experimental part of the research work on the effectiveness of next generation chemosorbents confirmed the apparent achievement of results and the rejection of new capabilities in a clinical approach to extracorporeal detoxifying modes of use and chemosorption by possession. The use of chemosorption as the main therapeutic option for headache disorders due to liver and kidney pathology has been identified in cases where other conditions are unsuccessful or ineffective. However, the use of fixed cost chemosorption in terms of treatment for patients remains unclear. The presence of chemical, hemodynamic, electrolytic, hormonal, immunological disorders prevents the prevalence of existing use in extracorporeal chemisorption.

Keywords: adsorption, carbonization, detoxication, hemosorbents, sorbent.

\section{INTRODUCTION}

Currently, research on the development of highly effective technologies for the integrated processing of production waste, which allows the most complete use of feedstock to produce chemical products, while avoiding the accumulation and ingress of harmful substances into the environment, is relevant. Promising raw materials for various functional materials useful to humans are large-tonnage agricultural waste, primarily those that concentrate on processing enterprises. As a result of processing rice grain into cereal, a lot of waste remains (up to 20\%), called rice husk (or husk), which contains unique porous layers of silica [1].

One of the methods that solve the problem of negative impact on the environment is the development of various materials based on production waste. Materials created on the basis of waste are used in medicine, pharmaceutical and chemical industries. For example, by processing rice husk, various sorbents, silicon, etc. can be obtained. For medical sorbents, the feedstock can be various wastes obtained from the processing of cereals. Medical sorbents include: enterosorbents and hemosorbents. As a result of waste processing, sorbents of plant origin can be obtained.

Hemosorbents must comply with the set of established medical and technical requirements, namely: biocompatibility with blood, high mechanical strength and pronounced sorption ability over a wide range of harmful and toxic substances that accumulate in the blood of patients. Only materials with a given surface chemistry, developed porosity in a fairly wide range of pore sizes, and significant values of the specific surface area of internal pores can satisfy these requirements. 
To remove hydrophobic molecules from the blood that are firmly bound to blood plasma albumin, as well as protein toxins and other high molecular weight toxic substances, hemosorbents are developed mass exchangers filled with sorption material [2]. Hemosorption is a method of removing toxic substances of medium molecular weight from the body during blood perfusion through a column filled with a selective or non-selective sorbent. Sorbent, mainly carbon, in direct contact with blood, adsorbs and absorbs toxic substances (creatinine, bilirubin, barbiturates, etc.), and purified blood is returned to the patient.

Using selective sorbents, specific toxic substances can be selectively sorbed. By changing the porous structure and, to some extent, the surface chemistry of carbon hemosorbents, one can achieve a targeted effect on the healing function of carbon hemosorbent. The main advantage of hemosorption is the rapid achievement of goals. Thanks to this, it is possible to save patients from ailments that are a direct threat to life. For example, peritonitis or acute pancreatitis. Given the particular importance of the detoxification of the body associated with environmental pollution, the development of ways to protect the internal environment (homeostasis) of a person from exposure to various kinds of xenobiotics is considered an urgent task of our time [3].

Designed for extracorporeal purification (detoxification) of blood, plasma and lymph from pathogenic microflora, exogenous and endogenous toxic substances, inflammatory mediators that cause septic conditions, mainly cytokines and endotoxins. A known method of producing hemosorbent from coal type IGIcombustible stones obtained by processing fossil fuels. It is characterized by a stable porous structure in the entire volume of the spherical granule. Its varieties differ both in the advantage of micropores and in variants with a predominance of transition pores and macropores [4]. The disadvantage of IGI-type combustible coals is the relatively high ash content and the release of sodium, potassium, calcium and other ions into the blood.

A known method of manufacturing a carbon material for hemosorption - a new generation of hemosorbent - carbon hemosorbent VNIITU-1, synthetic, meeting the requirements of medicine in full, having high compatibility with blood, mesoporous in surface structure, which is advantageous. The hemosorbent VNIITU-1 is characterized by high chemical purity (carbon content of at least $99.5 \%$, mineral impurities not more than $0.15 \%$ ), consists of strong round granules with a size of $0.5-1.0 \mathrm{~mm}$ (not less than $90 \%$ ) with a possible content of granules less than $0.5 \mathrm{~mm}$ in size - not more than $10 \%$; the total pore volume of its surface is $0.25-0.35 \mathrm{~cm} 3 / \mathrm{g}$, with a macropore volume of $0.02-0.04 \mathrm{~cm} 3 / \mathrm{g}$.

The disadvantage of the treatment method using hemosorbent VNIITU-1 is its lack of adsorption activity in relation to nitrogen-containing toxic substances that accumulate in the body with these diseases, in particular, bilirubin. All the hemosorbents described above have nonspecificity and low adsorption ability to substances of protein nature and toxic products. The raw material for the above sorbents is charcoal [5]. To obtain medical hemosorbent from plant materials, a study of the physicochemical properties of 5 types of samples of different composition was carried out.

\section{MATERIALS AND METHODS}

The object of study was carbonized rice husk. Carbonized rice husk is obtained by carbonization under isothermal conditions. The installation diagram is shown in Figure 1. The activation process was carried out as follows: the activator gas (CO2) was supplied starting from $300^{\circ} \mathrm{C}$, up to the selected activation temperature $\left(800^{\circ} \mathrm{C}\right)$, at which the activated carbon was still held for a certain time.

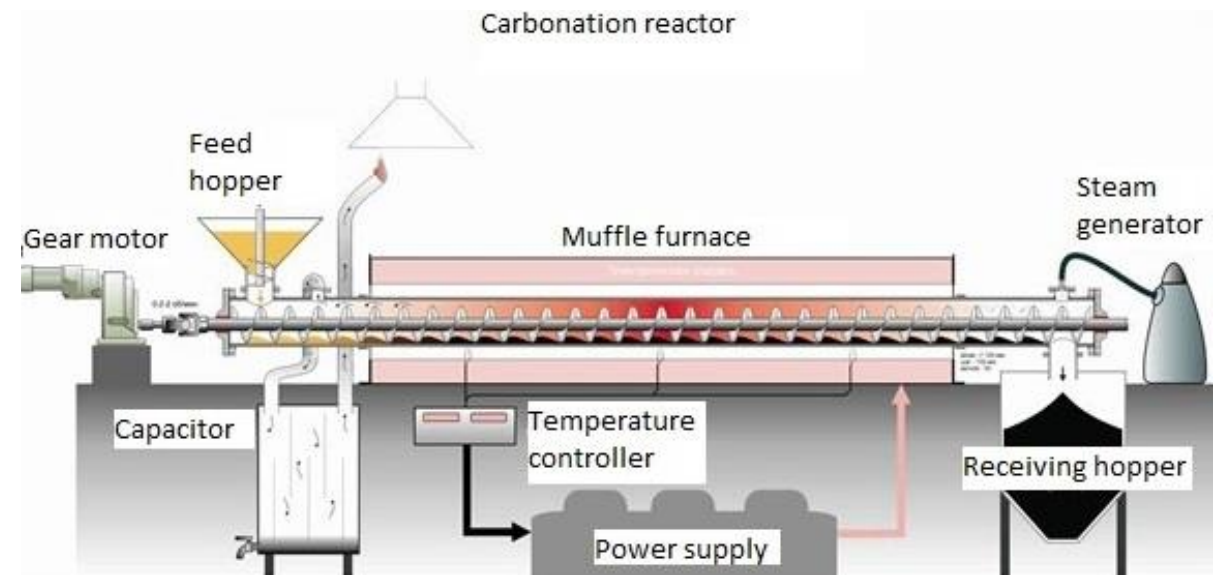

Figure 1: A reactor with a screw conveyor, a heater and an individual electric drive of a screw conveyor 
The reactor is designed for sequential dehydration of plant raw materials, accompanied by its depolymerization and partial decomposition in the temperature range from 650 to $800^{\circ} \mathrm{C}$ and accompanied by the removal of water (up to $280^{\circ} \mathrm{C}$ ), decarboxylation with the formation of pyrolysis resins with a combination of dehydration and decarbonylation in the range temperatures from 650 to $800^{\circ} \mathrm{C}$ (Figure 2).

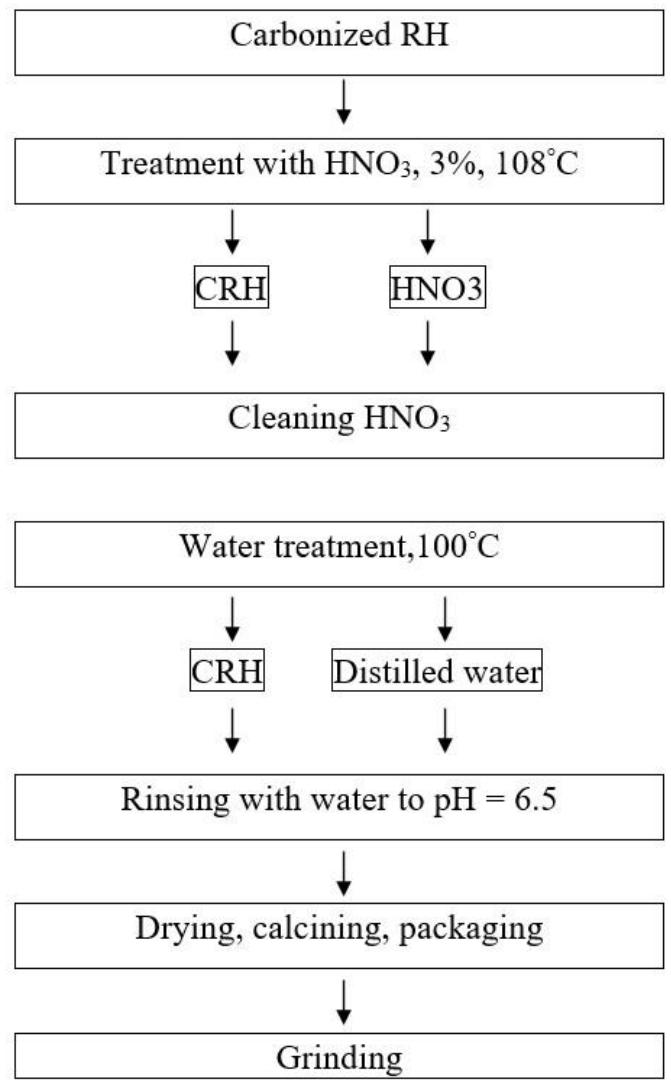

Figure 2: The scheme of demineralization with nitric acid

\section{RESULTS}

The process of demineralization of carbonized sorbents from rice husks was carried out in a glass container. The tank is equipped with a spiral electric heater. The heater is connected to a current source. The top of the tank is equipped with a reflux condenser to avoid leakage of nitric acid fumes. The demineralization process includes the following steps [6]:

A. The sorbent is placed in a container and poured with a mixture of a concentrated solution of nitric acid $(3 \%)$

B. Then this mixture is heated to a boil and boiled for 4 hours. After boiling, the mixture is left overnight for more complete demineralization.

C. After this, the spent hydrochloric acid is drained by decantation, the sorbent is transferred to another container and washed by boiling several times with distilled water to establish a neutral environment.

The obtained carbonized rice husk was modified with various reagents (carboxymethyl cellulose, dextrin) under various conditions. 4 samples were obtained from modified carbonized rice husks 35, 31ADMS, 14-2, decarbonized and 1 sample from charcoal [7].

The morphology and surface topography, elemental composition of the samples was studied by scanning electron microscopy using a Quanta 200i 3D electron microscope (Table 1). 
Table 1: The elemental composition of the samples

\begin{tabular}{l|c|c|c|c|c}
\hline \multirow{2}{*}{ INDICATORS } & $\mathbf{3 5}$ & $\begin{array}{c}\text { FROM } \\
\text { CHARCOAL }\end{array}$ & \multirow{3}{*}{ 31-ADMS } & $\mathbf{1 4 - 2}$ & DECARBONIZED \\
\cline { 2 - 6 } & \multicolumn{5}{|c|}{ UNIT - \% } \\
\hline $\mathrm{C}$ & 73.39 & 64.93 & 82.91 & 65.79 & - \\
\hline $\mathrm{O}$ & 12.14 & 18.56 & 8.00 & 15.02 & 44.22 \\
\hline $\mathrm{Na}$ & 1.09 & 0.57 & 0.87 & 1.46 & 3.85 \\
\hline $\mathrm{Mg}$ & 0.16 & 0.46 & 0.79 & - & 42.85 \\
\hline $\mathrm{Al}$ & 0.23 & 2.74 & 0.23 & - & 2.58 \\
\hline $\mathrm{Si}$ & 9.84 & 8.23 & 3.73 & 12.86 & 1.53 \\
\hline $\mathrm{P}$ & 0.22 & 0.73 & 0.08 & 2.65 & \\
\hline $\mathrm{Cl}$ & 0.54 & - & 0.23 & & \\
\hline $\mathrm{K}$ & 0.96 & 1.19 & 1.17 & & \\
\hline $\mathrm{Ca}$ & 0.42 & 0.76 & & & \\
\hline
\end{tabular}

The specific surface was determined by the BET method according to nitrogen adsorption data. Information on the micro / mesoporous texture (range from 17 to $3000 \AA$ ) of the RS sample was obtained by the method of low-temperature nitrogen adsorption on a 3H-2000PS1 instrument (Sorbtometer, specific surface area and porosity analyzer) after preliminary training of samples carried out at $150^{\circ} \mathrm{C}$ and a residual pressure of less than $0.001 \mathrm{mmHg}$ (Table 2).

Table 2: Measurement of the specific surface of hemosorbent

\begin{tabular}{c|c|c|c|c|c}
\hline $\begin{array}{c}\text { SPECIFIC SURFACE } \\
\text { AREA }\end{array}$ & $\mathbf{3 5}$ & $\begin{array}{c}\text { FROM } \\
\text { CHARCOAL }\end{array}$ & $\mathbf{3 1 - A D M S}$ & $\mathbf{1 4 - 2}$ & DECARBONIZED \\
\cline { 2 - 6 } & \multicolumn{5}{|c|}{ UNIT - m2/g } \\
\hline $\begin{array}{c}\text { Multithreaded BET } \\
\text { Method }\end{array}$ & 79.84 & 381.23 & 347.49 & 127.25 & 1.96 \\
\hline Single BET Method & 81.15 & 391.22 & 361.7 & 142.28 & 1.07 \\
\hline $\begin{array}{c}\text { Langmuir method } \\
\text { Micropore surface area } \\
\text { t-plot }\end{array}$ & 123.62 & 571.03 & 536.15 & 193.75 & 5.16 \\
\hline External surface area & 79.85 & 57.72 & 107.14 & 60.39 & \\
\hline
\end{tabular}

To determine the effectiveness of elimination of toxins by carbon hemosorbents, experiments were conducted on the hemosorption of ethanol from donated blood in vitro. For the experiment, pure donor blood was selected with a volume of $450 \mathrm{ml}(\mathrm{n}-10)$ into which $5 \mathrm{ml}$ of $33 \%$ ethyl alcohol was introduced. Blood was pumped using an "artificial kidney" device at a rate of $140 \mathrm{ml} / \mathrm{min}$. A photograph of a hemoperfusion experiment is shown in Figure 3.

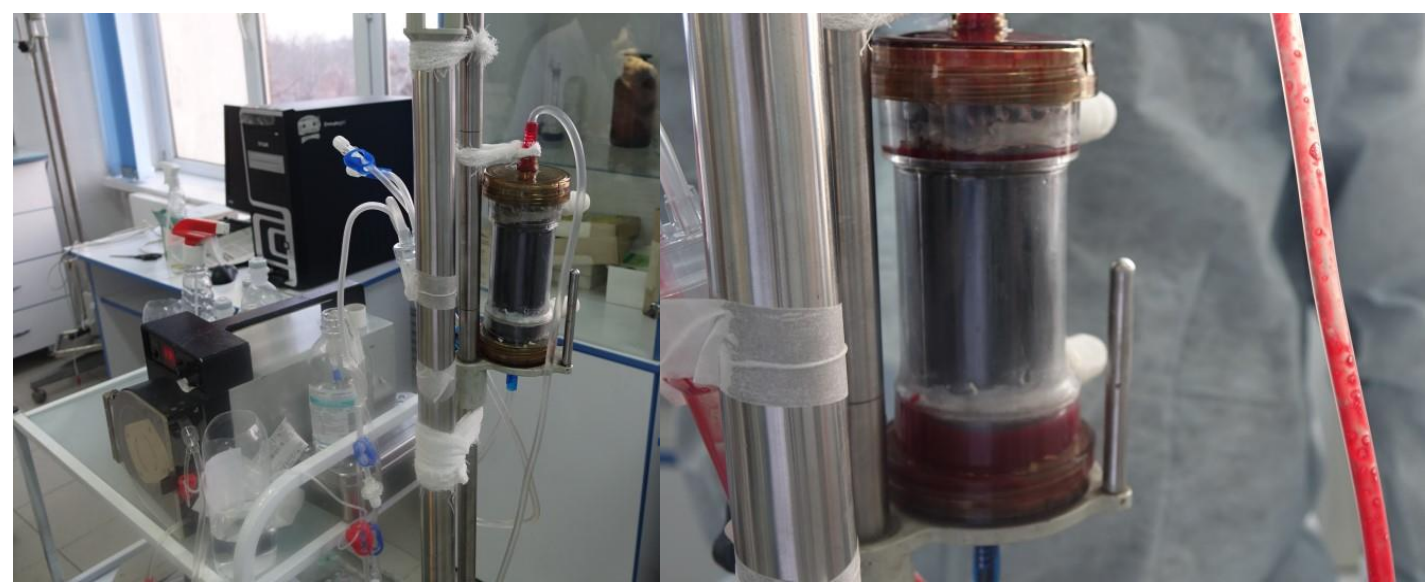

Figure 3: Elimination of ethanol from donated blood 
In the experiment, the effectiveness of three types of hemosorbents of the laminar flow was evaluated. Samples were 3 columns of hemosorbent:

No. 35 - activated: prepared according to the tested recipe and activated $\mathrm{CO} 2$ in a muffle furnace at $950^{\circ} \mathrm{C}$ for 1.5 hours

No. 14-2 - standard: prepared according to the tested recipe

No. 31-ADMS - de-treated: prepared according to the tried-and-tested recipe and desilicated by $10 \%$ $\mathrm{NaOH}$ solution with heating to $100^{\circ} \mathrm{C}$ in an oven (twice)

As a result, it was found that sorption by Hemosorbent No. 35 was 44\%, by Hemosorbent No. 14-2 was $9 \%$, and sorption by Hemosorbent No. 31-ADMS was $50 \%$.

Resistance during the passage of blood through the monolith was not observed. During the experiment, the observations showed the following characteristics: blood is dissected over the entire surface of the monolith into all cellular channels. The presence of water in the case was observed (during manufacture, the carbon monolith was washed with water, the presence of water in the cartridge can cause hemolysis of the blood (destruction of red blood cells with the release of hemoglobin into the environment)). At the bottom of the case, there is noticeable discharge of blood inside (Figure 3). According to the sorption of ethanol, the high sorption ability was shown by sample No. 31-ADMS - Deseminated Hemosorbent.

The experimental part of the research work on the effectiveness of new generation hemosorbents confirms the expected results and opens up new possibilities in the clinical application of extracorporeal detoxification methods in general and hemosorption in particular.

Research results. As can be seen in the images of electron miscroscopy, samples of charcoal and carbonized rice husk (35, 31-ADMS, 14-2) have a developed porous structure consisting of meso and micropores. Porosity determines the direction of sorbents in medicine. When micropores are present, carbon sorbents are used to remove from biological fluids. The porous structure of the sorbent is the basis for the effective sorption of toxins. The efficiency of sorption of toxins is determined by the porous structure of the main classes of sorbents according to qualitative and quantitative indicators. The developed porous structure provides most of the requirements for hemosorbents. When toxic substances are removed, the main mechanism of sorption is physical adsorption due to the action of dispersion forces.

\section{DISCUSSION}

The studies performed showed that with the help of rice husk it is possible to produce carbon materials with a developed porous structure, which can be used as hemosorbents. The sorbent obtained by the carburization of rice husk consists of layers of carbon atoms that are assembled into hexagonal structures. But if in graphite the layers are oriented strictly parallel to each other, then in the nanostructured carbon sorbent there are fewer orders of magnitude: the layered segments are shifted relative to each other [8].

Between such variously oriented layers there is free space - micro- and mesopores, the size of which can be from 0.5 to 7 nanometers. On the walls are micro- and mesopores and molecules of various toxic substances with low and medium molecular weights are held. In addition, the study revealed that the process for the production of carbon materials has no waste, i.e. on a production scale, wasteless production is possible. It was established that, unlike sorbents with high adsorption activity, which absorb both useful and toxic substances, demineralized KRS has an average adsorption capacity. The average value allows you to selectively sorb only toxic substances.Based on the obtained EMR data, it follows that the sorbent based on CRH has pores that are able to sorb toxic substances and not sorb substances useful for the body $[9,10]$.

Currently, the use of carbon materials as medical sorbents is especially important. Carbon materials porous carbon bodies, granular and powdery, having a large specific surface for the adsorption of dissolved and gaseous substances.

The adsorption properties of coal are estimated by the amount of a model substance adsorbed by a unit mass of coal under certain conditions (until it is completely saturated in comparison with a reference sample or solution), as well as by the time of the protective action of a unit volume of coal until it is completely saturated. Recently, carbon materials have been considered as a possible effective blood purifier in connection with the problem of sepsis.

Endogenous intoxication in patients with liver and kidney pathologies is the main justification for the use of hemosorption in complex therapy, which allows you to remove circulating toxic products of large molecular structure from the blood. Only direct contact of the sorbent with blood allows as a result of sorption on the surface of the granules to remove complex complexes of albumin + toxin, lipids + toxin from the body, which are the main obstacle to the effective use of other types of hemocorrections. The use of 
hemosorption as the main therapeutic method for intoxication syndrome due to pathology of the liver and kidneys is justified in cases where other therapeutic measures are ineffective or unsuccessful.

However, the use of hemosorption in a complex of intensive care measures for patients with diseases of the hepatoduodenopancreal region has not yet become widespread. The presence of hemic, hemodynamic, electrolyte, hormonal, immunological disorders, to a large extent, inhibits the widespread use of existing methods of extracorporeal hemosorption.

\section{CONCLUSIONS}

The sorbent obtained on the basis of CRH binds toxic substances in the blood, thereby preventing or attenuating the clinical manifestations of endotoxemia, including symptoms of intoxication and toxicosis. The use of the hemosorbent on the basis of $\mathrm{CRH}$ is capable of adsorbing various toxic substances into the digestive canal entering into a chemical reaction with them. Unlike other sorbents, which in the process of sorption delay, along with molecules of toxins and molecules of useful substances in their pores, sorbent based on CRH selectively and precisely densely surrounds molecules of only toxic substances, sticks them out and out.

The granular hemosorbents used until recently partially traumatize the formed elements of the blood, which creates the preconditions for thrombosis in violation of the integrity of the erythrocyte membranes. In addition, when granules collide, "latent dust" can form, which due to its chemical composition can cause various kinds of reactions.

The developed hemosorbent during blood purification minimizes the destruction of the formed elements due to the laminar flow of blood in the forward flow, which increases its efficiency compared to other hemosorbents. In addition to this, it should be noted that the efficiency of granular sorbents is relatively low due to the small (15-20\%) active surface of the sorbent, whereas when using mesoporous carbon sorbents with a laminar flow, the active surface can be calculated with high accuracy, which will allow individualizing the approach to each patient in a timely manner to make adjustments to the flow rate, GS time, which ultimately will affect the effectiveness of the procedure itself.

\section{BIBLIOGRAPHY}

[1] IVLEVA, A.R., KANARSKIJ, A.V., KAZAKOV, YA.V., et al., "Interrelation of morphological and adsorption properties of hardwood pulp", Vestnik Kazanskogo tekhnologicheskogo universiteta, v. 17, n. 23, pp. 208-211, 2014.

[2] HOLMOVA, M.A., TERENT'EV, K.YU., KAZAKOV, YA.V., et al., "Technological properties of sulfate deciduous whiten cellulose treated with endoglucanase enzyme preparation p. Verruculosum", Vestnik Kazanskogo tekhnologicheskogo universiteta, v. 18, n. 5, pp. 101-104, 2015.

[3] PETROV, A.Yu., GAVRILOV, A.C., GUSELNIKOVA, E.V., "Technology for activated carbon tablets achieving", Khimiko-farmatsevticheskiy zhurnal, v. 38, n. 1, pp. 41-44. 2004.

[4] NIKOLAEV, V.G., "Enterosorption: State of the issue and prospects for the future", Vestnik problem biologii i mediciny, n. 4, pp. 7-17, 2007.

[5] PALIJ, N.G., REZNICHENKO, I.G., "The use of enterosgel detoxicant for the treatment of diseases of the gastrointestinal tract”, Novosti mediciny i farmacii, v. 9, n. 149, p. 8, 2004.

[6] PALIJ, N.G., REZNICHENKO, I.G., "A modern view of the problem of enterosorption: the choice of the optimal drug”, Novosti mediciny i farmacii, v. 1, n. 217, p. 217, 2007.

[7] NURALIEV, M.A., BAYASHEV, B.B., DOSYMBETOVA, M.I., et al., "Biochemical changes in the urinary system with the use of the Fitosorb-Altyn Zhebe biologically active supplement", News of the National Academy of Sciences of the Republic of Kazakhstan, n. 6, pp. 59-64, 2017.

[8] BIJSENBAEV, M.A., NURALIEV, M.A., NURALY, A.M, ey al., "The use of carbonized rice husk in the manufacture of a carbon monolith for hemosorption", Colloquium journal, n. 17, pp. 74-80, 2018.

[9] SHAMOV, B.A., MALANICHEVA, T.G., "The effectiveness of enterosorption in the correction of endoxinemia syndrome in atopic dermatitis in children", Lechashchij vrach, n. 8, pp. 5-6, 2010.

[10] MUTUSHEV, A.ZH., AKNAZAROV, S.H., GOLOVCHENKO, O.YU., et al., "Nanostructured carbon material for enterosorpption", Poster CARBON-2021. 


\section{ORCID}

Assiya Nuraly Sestager Akhnazarov

https://orcid.org/0000-0001-8361-2982

Esin Apaydin-Varol

https://orcid.org/0000-0002-3948-938X

Ulpan Amzeyeva

https://orcid.org/0000-0002-2323-0365

https://orcid.org/0000-0003-3962-0701

Alibek Mutushev

https://orcid.org/0000-0002-5047-5608 